01,05

\title{
Влияние ионного облучения на магнитные свойства пленок CoPt
}

\author{
(С) И.Л. Калентьева ${ }^{1}$, О.В. Вихрова ${ }^{1}$, Ю.А. Данилов ${ }^{1}$, А.В. Здоровейщев ${ }^{1}$, М.В. Дорохин ${ }^{1}$, \\ Ю.А. Дудин ${ }^{1}$, А.В. Кудрин ${ }^{1}$, М.П. Темирязева ${ }^{2}$, А.Г. Темирязев ${ }^{2}$, \\ С.А. Никитов ${ }^{3,4,5}$, А.В. Садовников ${ }^{3,4}$
}

${ }^{1}$ Научно-исследовательский фризико-технический институт

Нижегородского государственного университета им. Н.И. Лобачевского,

Нижний Новгород, Россия

${ }^{2}$ Фрязинский фрилиал Института радиотехники и электроники им. В.А. Котельникова РАН, Фрязино, Россия

3 Лаборатория „Магнитные метаматериалы“ Саратовского государственного университета, Саратов, Россия

${ }^{4}$ Институт радиотехники и электроники им. В.А. Котельникова РАН,

Москва, Россия

${ }^{5}$ Московский фризико-технический институт,

Долгопрудный, Россия

E-mail: istery@rambler.ru

Поступила в Редакцию 17 ноября 2020 г.

В окончательной редакции 17 ноября 2020 г.

Принята к публикации 19 ноября 2020 г.

Исследована возможность использования имплантации ионов $\mathrm{He}^{+}$с энергией $20 \mathrm{keV}$ для модифицирования доменной структуры и магнитных свойств сформированных методом электронно-лучевого испарения пленок $\mathrm{CoPt}$ с различным содержанием кобальта $-\mathrm{Co}_{0.45} \mathrm{Pt}_{0.55}$ и $\mathrm{Co}_{0.35} \mathrm{Pt}_{0.65}$. Для облученных образцов CoPt обоих составов обнаружено уменьшение коэрцитивного поля (сужение петли гистерезиса на магнитиополевых зависимостях угла Фарадея и намагниченности) с увеличением флюенса ионов $\mathrm{He}^{+}$от $2 \cdot 10^{14}$ до $4 \cdot 10^{14} \mathrm{~cm}^{-2}$. При этом остаточная намагниченность пленок $\mathrm{Co}_{0.35} \mathrm{Pt}_{0.65}$ совпадает с намагниченностью насыщения, а для $\mathrm{Co}_{0.45} \mathrm{Pt}_{0.55}$ наблюдается уменьшение остаточной намагниченности.

Методом магнитно-силовой микроскопии показано, что для сплава $\mathrm{Co}_{0.45} \mathrm{Pt}_{0.55}$ с увеличением флюенса ионов до $3 \cdot 10^{14} \mathrm{~cm}^{-2}$ образуется наибольшее число круглых изолированных доменов (скирмионов), a для облученных $\mathrm{He}^{+}$с флюенсом $4 \cdot 10^{14} \mathrm{~cm}^{-2}$ пленок $\mathrm{Co}_{0.35} \mathrm{Pt}_{0.65}$, кроме изолированных круглых доменов, наблюдаются 360-градусные доменные стенки (1D-скирмионы). При этом изучение пленок CoPt методом Мандельштам-Бриллюэновской спектроскопии выявило увеличение сдвига между стоксовой и антистоксовой компонентами спектра и значительное усиление взаимодействия Дзялошинского-Мория в облученных образцах.

Проведение модельных расчетов посредством программы SRIM показало, что применяемое ионное облучение способствует ассимметричному перемешиванию атомов Со и $\mathrm{Pt}$ в пленках $\mathrm{CoPt}$, и это может лежать в основе механизма наблюдаемых эффектов влияния ионного облучения на их магнитные свойства и доменную структуру.

Ключевые слова: электронно-лучевое испарение, ферромагнитный сплав, ионное облучение, магнитные свойства, доменная структура, магнитно-силовая микроскопия, взаимодействие Дзялошинского-Мория, скирмионы.

DOI: 10.21883/FTT.2021.03.50580.240

\section{1. Введение}

Тонкие пленки ферромагнитного сплава CoPt обладают рядом уникальных спин-зависимых характеристик, в частности, наличие сильной магнитной одноосной анизотропии и интерфейсного (на границе раздела ферромагнитного $(\mathrm{Co})$ и немагнитного слоев $(\mathrm{Pt}))$ взаимодействия Дзялошинского-Мория (ВДМ) создают условия для существования в таких пленках наноразмерных магнитных структур - скирмионов [1,2]. Формирование стабильных скирмионных структур в нулевом магнитном поле при комнатной температуре является важным фактором, определяющим применение тонкопленочных ферромагнитных сплавов CoPt в приборных структурах спинтроники.

Одним из современных способов получения скирмионов является формирование дефектов в магнитной многослойной пленке. Установлено, что наличие дефектов в пленках не только локализует зарождение скирмионов, но и снижает энергетический барьер их формирования [3-5].

Новый метод зарождения скирмионов в области дефектов нанометрового размера, созданных посредством облучения сфокусированным ионным пучком $\mathrm{Ga}^{+}$ поликристаллических магнитных многослойных образцов с интерфейсным взаимодействием Дзялошинского- 
Мория, представлен в работе [6]. В этой работе исследования проведены на структурах с повторяющимися слоями $[\mathrm{Ir} / \mathrm{Co} / \mathrm{Pt}]$ и $[\mathrm{Pt} / \mathrm{Co} / \mathrm{Ru}]$, изготовленных методом магнетронного распыления. Размер скирмиона в такой многослойной системе определяется величиной взаимодействия Дзялошинского-Мория, магнитной анизотропией, обменным взаимодействием и намагниченностью насыщения. Также сообщалось о формирования уникальных спиновых конфигураций: искусственных скирмионов и антискирмионов (стабильных при комнатной температуре) в сплошных многослойных пленках $[\mathrm{Co}(0.3 \mathrm{~nm}) / \mathrm{Pt}(1.0 \mathrm{~nm})]_{\times 8}$ без использования слоев дополнительного материала с помощью облучения ионами $\mathrm{Ga}^{+}$(с энергией $30 \mathrm{keV}$ и флюенсом $1.46 \cdot 10^{13} \mathrm{~cm}^{-2}$ ) [7].

В работе [8] многослойные структуры $[\mathrm{Co}(0.5 \mathrm{~nm}) / \mathrm{Pt}(1 \mathrm{~nm})]_{\times 5}$, выращенные методом магнетронного осаждения, были модифицированы сфокусированным пучком ионов $\mathrm{He}^{+}$(с энергией $30 \mathrm{keV}$ и флюенсом $1 \cdot 10^{15} \mathrm{~cm}^{-2}$ ). В результате в пленке был сформирован массив размером $20 \times 14 \mu \mathrm{m}^{2}$, состоящий из областей цилиндрической формы диаметром около $100 \mathrm{~nm}$ с пониженной анизотропией. Обнаружено, что при сканировании образца на малых высотах наблюдаются эффекты перемагничивания скирмионов под действием поля зонда магнитно-силовой микроскопии [8].

Ранее нами было продемонстрировано влияние ионного облучения на магнитные свойства сплава $\mathrm{Co}_{0.45} \mathrm{Pt}_{0.55}$, сформированного методом электронно-лучевого испарения в высоком вакууме [9]. Методом магнитно-силовой микроскопии показано, что при облучении ионами $\mathrm{He}^{+}$ с энергией $20 \mathrm{keV}$ и флюенсом $3 \cdot 10^{14} \mathrm{~cm}^{-2}$ в слое $\mathrm{Co}_{0.45} \mathrm{Pt}_{0.55}$ наблюдается активация образования изолированных круглых доменов (магнитных скирмионов). При этом методом мандельштам-бриллюэновской спектроскопии было установлено, что происходит усиление взаимодействия Дзялошинского-Мория в облученном слое $\mathrm{Co}_{0.45} \mathrm{Pt}_{0.55}$.

В данной работе представлены результаты исследования возможности управляемого радиационного воздействия на магнитные свойства изготовленных методом электронно-лучевого испарения пленок ферромагнитного сплава CoPt с различным содержанием кобальта.

\section{2. Методика эксперимента}

Тонкие ферромагнитные пленки сплава $\mathrm{CoPt}$ были сформированы методом электронно-лучевого испарения (ЭЛИ) мишеней из высокочистых материалов при температуре $200^{\circ} \mathrm{C}$ в высоком вакууме. Для этого на подложки полуизолирующего GaAs поверх предварительно осажденного тонкого диэлектрического слоя $\mathrm{Al}_{2} \mathrm{O}_{3}$ (толщиной $\sim 1 \mathrm{~nm}$ ), предотвращающего диффузию кобальта в полупроводник [10], поочередно наносились слои $\mathrm{Pt}$ и Со с десятикратным повтором: $[\mathrm{Co}(0.3 \mathrm{~nm}) / \mathrm{Pt}(0.5 \mathrm{~nm})]_{\times 10}-\operatorname{CoPt}(3 / 5)$ и $[\operatorname{Co}(0.2 \mathrm{~nm}) / \operatorname{Pt}(0.5 \mathrm{~nm})]_{\times 10}-\operatorname{CoPt}(2 / 5)$. Таким образом, были сформированы металлические пленки двух составов, общая толщина которых составляла $8 \mathrm{~nm}$ $(\operatorname{CoPt}(3 / 5))$ и $7 \mathrm{~nm}(\operatorname{CoPt}(2 / 5))$ соответственно.

Как было показано ранее с использованием рентгеновской фотоэлектронной спектроскопии с послойным профилированием по глубине, указанное выше соотношение толщин слоев $\operatorname{CoPt}(3 / 5)$ соответствует сплаву $\mathrm{Co}_{0.45} \mathrm{Pt}_{0.55}[11]$. Исследования структурных свойств пленок CoPt посредством просвечивающей электронной микроскопии обнаружили, что они являются поликристаллическими и не демонстрируют „слоистости“, обусловленной поочередным осаждением слоев $\mathrm{Pt}(0.5 \mathrm{~nm})$ и $\mathrm{Co}(0.3 \mathrm{~nm})$ [12]. В случае структур $\operatorname{CoPt}(2 / 5)$ была проведена технологическая (по времени нанесения) оценка состава полученного сплава, которая показала соотношение $-\mathrm{Co}_{0.35} \mathrm{Pt}_{0.65}$.

Кроме того, было установлено, что полученные данным методом тонкие пленки CoPt имеют ось легкого намагничивания, перпендикулярную плоскости слоя, и сохраняют остаточную намагниченность при комнатной температуре $[13,14]$. Описанные свойства пленок $\mathrm{CoPt}$ делают их привлекательными для использования в приборах, работающих на основе магнитооптических эффектов $[14,15]$. Помимо этого было обнаружено, что при сканировании таких пленок магнитным зондом атомносилового микроскопа происходит перестройка их доменной структуры с образованием изолированных круглых доменов (магнитных скирмионов) или 360-градусных доменных границ (1D-скирмионов) [16,17].

Полученные структуры $\operatorname{CoPt}(3 / 5)$ и $\operatorname{CoPt}(2 / 5)$ разделялись на образцы размером $6 \times 6 \mathrm{~mm}^{2}$ и равномерно облучались на ускорителе ИЛУ-3 ионами $\mathrm{He}^{+}$с энергией $20 \mathrm{keV}$ при значениях флюенса ионов $2 \cdot 10^{14}, 3 \cdot 10^{14}$ и $4 \cdot 10^{14} \mathrm{~cm}^{-2}$ (схематические изображения изготовленных структур и эксперимента по ионному облучению показаны на рис. 1).

Выбор энергии и диапазона изменения флюенса ионов гелия был сделан с учетом расчетов распределения возникающих дефектов по глубине структур, проведенных с использованием программы SRIM [18], и калькулятора, позволяющего делать оценки коэффициента распыления материала при ионном облучении [19]. Расчеты с использованием программы SRIM показывают, что в результате ионного воздействия с выбранными параметрами может наблюдаться значительное проникновение атомов кобальта и платины в слой диэлектрика $\mathrm{Al}_{2} \mathrm{O}_{3}$, о чем свидетельствует представленные на рис. 1 распределения атомов отдачи $(\mathrm{Co}, \mathrm{Pt})$ по глубине структуры. Отметим, что кислород и алюминий практически не попадают в пленку CoPt (концентрация атомов $\mathrm{Al}$ и $\mathrm{O}$ много менее $1 \cdot 10^{20} \mathrm{~cm}^{-3}$ и только в слое не более $\left.1 \mathrm{~nm}\right)$. Расчеты также показывают, что слой $\mathrm{Al}_{2} \mathrm{O}_{3}$ толщиной $1 \mathrm{~nm}$ при выбранных условиях ионного облучения эффективно препятствует проникновению атомов Со и Pt в полупроводниковую часть структуры (расчеты профилей атомов отдачи $\mathrm{Co}$ и $\mathrm{Pt}$ в полупроводник без слоя $\mathrm{Al}_{2} \mathrm{O}_{3}$ дают концентрации атомов $\sim(1-3) \cdot 10^{20} \mathrm{~cm}^{-3}$ на глубине до $1.5 \mathrm{~nm}$ в GaAs, что нежелательно с точки зрения сохранения электрофизических параметров арсенида галлия). 

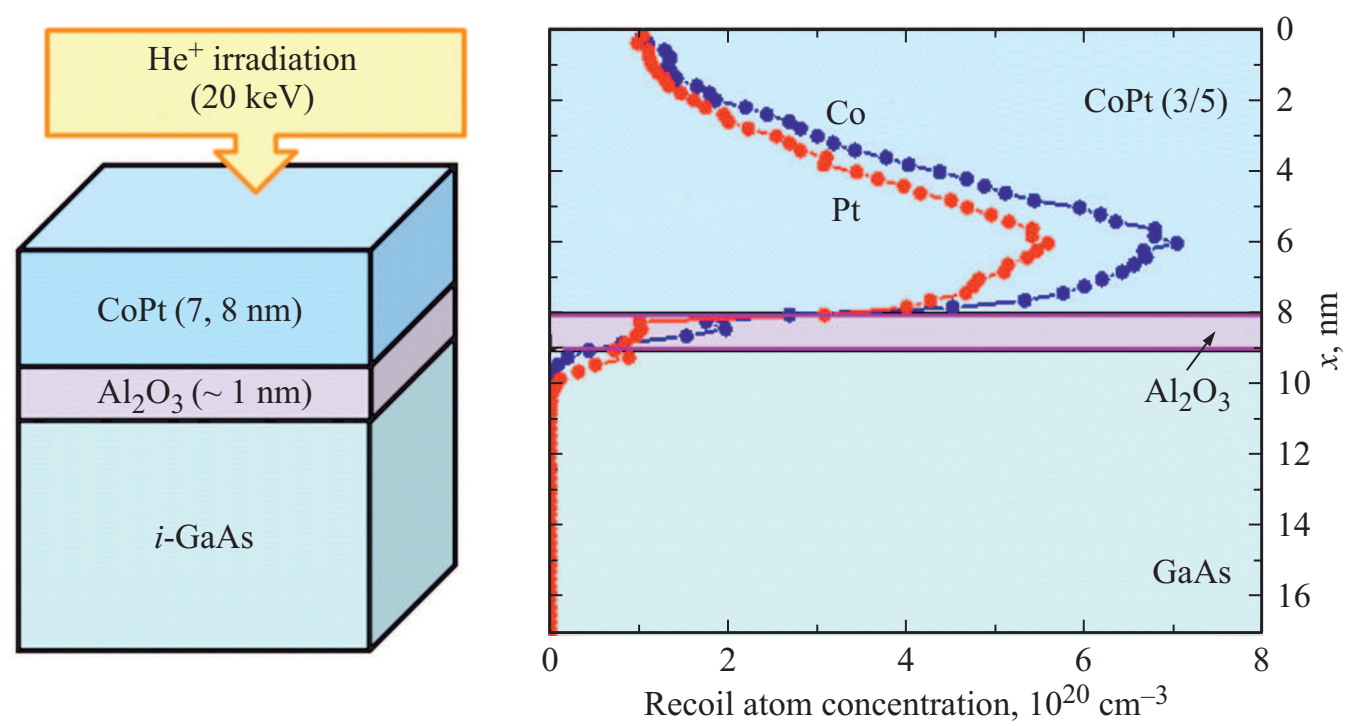

Рис. 1. Схематические изображения изготовленных структур и эксперимента по ионному облучению. Рассчитанные с помощью программы SRIM [18] распределения атомов отдачи $(\mathrm{Co}, \mathrm{Pt})$ по глубине структуры. Энергия ионов $\mathrm{He}^{+}$составляла $20 \mathrm{keV}$, флюенс ионов $=3 \cdot 10^{14} \mathrm{~cm}^{-2}$.

На исходных и облученных образцах исследовался магнитооптический эффект Фарадея (внешнее магнитное поле прикладывается перпендикулярно поверхности пленок) на длине волны лазерного излучения $980 \mathrm{~nm}$, и анализировались магнитополевые зависимости угла Фарадея $\left(Q_{F}\right)$ в поле от 0 до \pm 4500 Ое. Намагниченность $(M)$ образцов измерялась посредством магнитометра с переменным градиентом поля в диапазоне полей \pm 1700 Oe.

Морфология поверхности и доменная структура исходных и облученных образцов исследовались методами атомно- и магнитно-силовой микроскопии (АСМ и МСM) при помощи атомно-силового микроскопа SmartSPM (AIST-NT) с использованием зондов двух типов: специально изготовленных нами кантилеверов с очень низким магнитным моментом, минимизирующим их воздействие на магнитную структуру [20], и зондов PPP-LM-MFMR (Nanosensors). Для изучения изменений доменной структуры под действием пространственно неоднородного магнитного зонда применялись специальные методики, описанные в [17].

Были проведены исследования образцов методом мандельштам-бриллюэновской спектроскопии (МБС), который позволяет изучать дисперсионные характеристики спиновых волн в магнетиках и производить оценку пространственно-неоднородной прецессии магнитных моментов (спиновых возбуждений с различными волновыми числами) в ферро- и ферримагнитных материалах $[2,21]$ на частотах в диапазоне от 1 до $1000 \mathrm{GHz}$. Методика измерения основана на невзаимном характере спин-волновых возбуждений в пленках с ассиметричным обменным взаимодействием [2]. По анализу сдвигов стоксовой и антистоксовой частот рассеяния Мандельштам-Бриллюэна оценивалась величина энергии взаимодействия Дзялошинского-Мория - ключевой параметр при интерпретации скирмионных состояний в магнитной среде [2,22]. При этом для увеличения точности измерения для каждого образца проводилось накопление спектров в течение двадцати часов с последующим изменением ориентации приложенного относительно поверхности пленки магнитного поля.

Все исследования были проведены при комнатной температуре.

\section{3. Экспериментальные результаты}

Магнитополевые зависимости угла Фарадея $\left(Q_{F}(H)\right)$ и намагниченности $(M(H))$ для образцов $\mathrm{CoPt}$ обоих составов имеют подобный вид (рис. 2, $a, c$ ): коэрцитивное поле и величина магнитного поля, при котором наблюдается выход на насыщение перечисленных характеристик, совпадают для обоих методов исследования. В случае исходных образцов зависимости $Q_{F}(H)$ и $M(H)$ содержат петлю гистерезиса с коэрцитивным полем $\left(H_{C}\right)$ $\sim 400$ Ое для $\operatorname{CoPt}(3 / 5)$ и $\sim 700$ Ое для $\operatorname{CoPt}(2 / 5)$, причем величина остаточной намагниченности $\left(M_{R}\right)$ практически совпадает с намагниченностью насыщения $\left(M_{S}\right)$.

Влияние ионного облучения на поведение магнитополевых зависимостей намагниченности и угла Фарадея для пленок $\operatorname{CoPt}(3 / 5)$ и $\operatorname{CoPt}(2 / 5)$ продемонстрировано на рис. $2, b$ и $d$. Здесь приведены характеристики относительных величин остаточной намагниченности $\left(M_{R} / M_{S}\right)$ и коэрцитивного поля при изменении флюенса ионов $\mathrm{He}^{+}$от $2 \cdot 10^{14}$ до $4 \cdot 10^{14} \mathrm{~cm}^{-2}$. Видно, что для облученных образцов СoPt обоих составов наблюдается постепенное уменьшение коэрцитивного поля (сужение петли гистерезиса на зависимостях $Q_{F}(H)$ и $\left.M(H)\right)$ с увеличением флюенса ионов). Поведение относительных величин остаточной намагниченности после ионной 

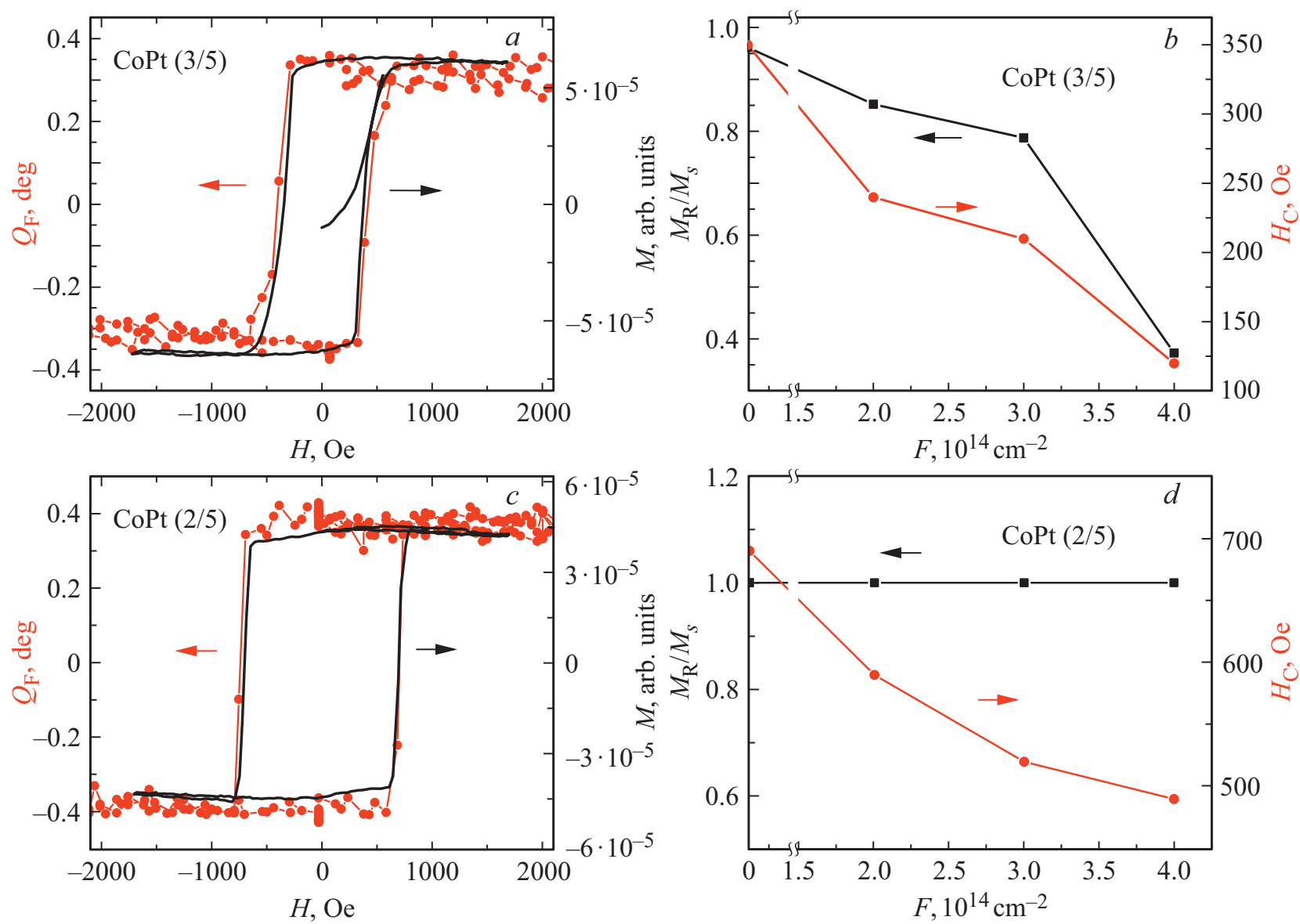

Рис. 2. Магнитополевые зависимости угла Фарадея и намагниченности исходных структур $\operatorname{CoPt}(3 / 5)(a)$ и $\operatorname{CoPt}(2 / 5)(c)$; зависимости коэрцитивного поля $\left(H_{C}\right)$ и относительных величин остаточной намагниченности $\left(M_{\mathrm{R}} / M_{\mathrm{S}}\right)$ от флюенса ионов гелия для структур $\operatorname{CoPt}(3 / 5)(b)$ и $\operatorname{CoPt}(2 / 5)(d)$. Внешнее магнитное поле при исследованиях угла Фарадея и намагниченности было приложено перпендикулярно поверхности пленки CoPt.

имплантации демонстрирует различный характер для пленок $\operatorname{CoPt}(3 / 5)$ и $\operatorname{CoPt}(2 / 5)$. Для облученных образцов структуры $\operatorname{CoPt}(2 / 5)$ остаточная намагниченность продолжает совпадать с намагниченностью насыщения, при этом петля на зависимостях $Q_{F}(H)$ и $M(H)$ остается „прямоугольной“, в то время как для структуры $\operatorname{CoPt}(3 / 5)$ наблюдается уменьшение относительных величин остаточной намагниченности и появление наклона петли гистерезиса с увеличением флюенса ионов.

АСМ-исследования выявили, что шероховатость исходных и облученных пленок CoPt остается низкой, а величина среднеквадратичной высоты неровностей не превышает $\sim 0.5 \mathrm{~nm}$, т. е., используемое в экспериментах ионное облучение не привело к возникновению заметных изменений в морфологии поверхности образцов.

Доменная структура исходных и облученных образцов была исследована методом МСМ в „стандартном“ режиме сканирования пленок в два прохода. При этом использовался зонд, имеющий крайне низкий магнитный момент и не вносящий изменения в исследуемую магнитную структуру. Полученные данные представлены на pис. 3 (фрагменты $a, c, e, g)$ для пленки $\operatorname{CoPt}(3 / 5)$ и на pис. 4 (фрагменты $a, c, e, g)$ для пленки $\operatorname{CoPt}(2 / 5)$. Как видно из представленных МСМ-изображений, исходная пленка $\operatorname{CoPt}(3 / 5)$ имеет более мелкую лабиринтную структуру (ширина доменов $\sim 100-200 \mathrm{~nm}$ ) по сравнению с исходным образцом структуры $\operatorname{CoPt}(2 / 5)$, где домены значительно крупнее (рис. $4, a)$. Следует отметить, что для обоих исследуемых составов CoPt заметных изменений доменной структуры в результате облучения ионами гелия с флюенсом в диапазоне от $2 \cdot 10^{14}$ до $4 \cdot 10^{14} \mathrm{~cm}^{-2}$ не наблюдается.

Сканирование пленок зондом Nanosensor, имеющим более высокое значение магнитного момента, приводит к изменению доменной структуры. Вначале в два прохода проводится сканирование области $2 \times 2 \mu \mathrm{m}^{2}$, при этом в области сканирования пленка частично перемагничивается под воздействием зонда. Затем в один проход на расстоянии порядка $100 \mathrm{~nm}$ над поверхностью сканируется большая по размеру область $5 \times 5 \mu \mathrm{m}^{2}$ (рис. 3 для $\operatorname{CoPt}(3 / 5)$ и рис. 4 для $\operatorname{CoPt}(2 / 5)$, фрагменты $b, d, f, h)$.

При сканировании участка исходного образца $\operatorname{CoPt}(3 / 5)$ магнитным зондом Nanosensor, проходящим близко к поверхности, доменная структура существенным образом изменяется: под воздействием поля зонда образуется светлый $2 \times 2 \mu \mathrm{m}^{2}$ участок, соответствую- 


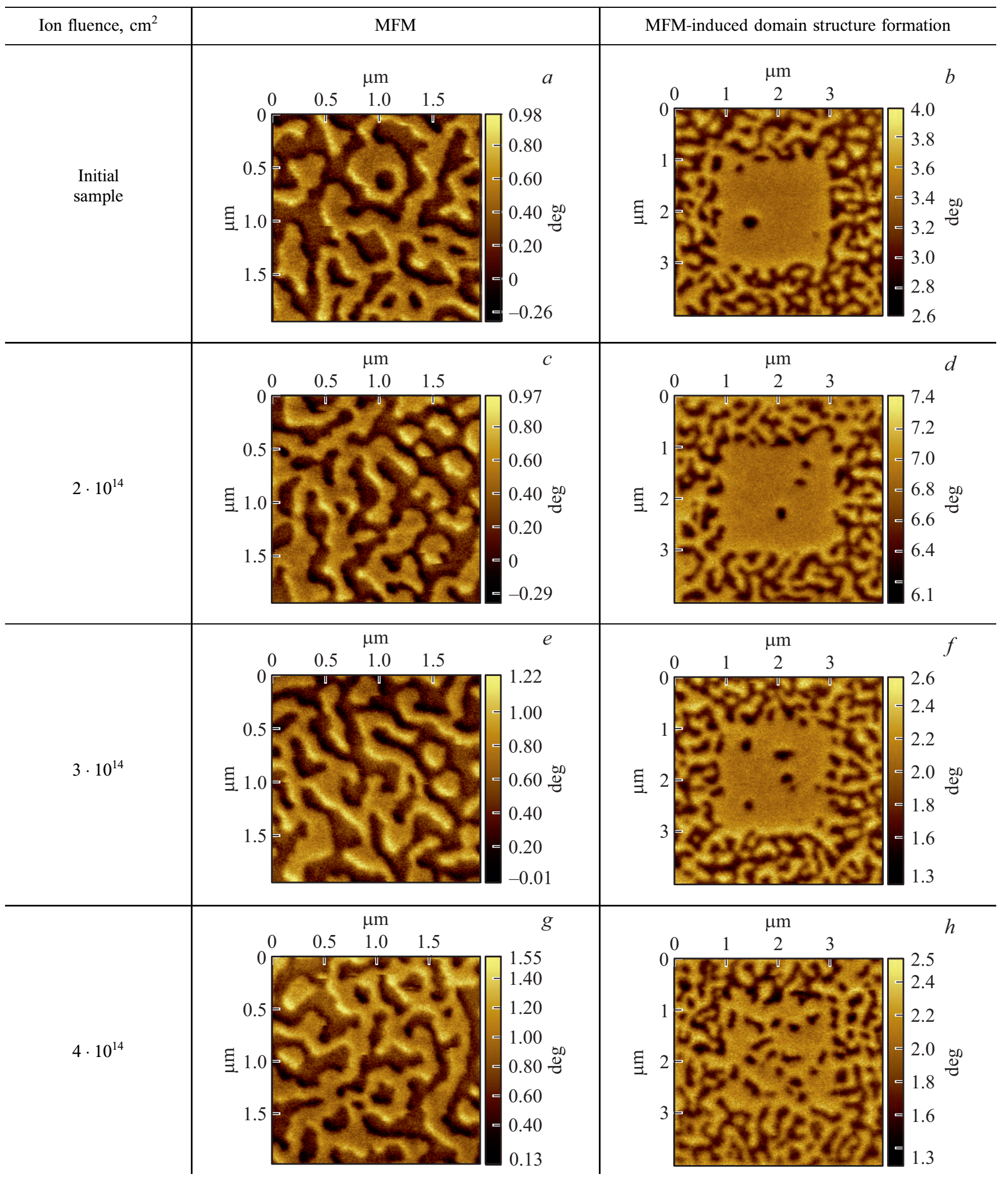

Рис. 3. МСМ-изображения исходного и облученного ионами $\mathrm{He}^{+}(20 \mathrm{keV})$ с различными флюенсами образцов пленок СоРt $(3 / 5)$, полученные двумя способами сканирования (зондом с покрытием CoPt - (MCM) и зондом Nanosensor (MCM-создание доменной структуры)). 


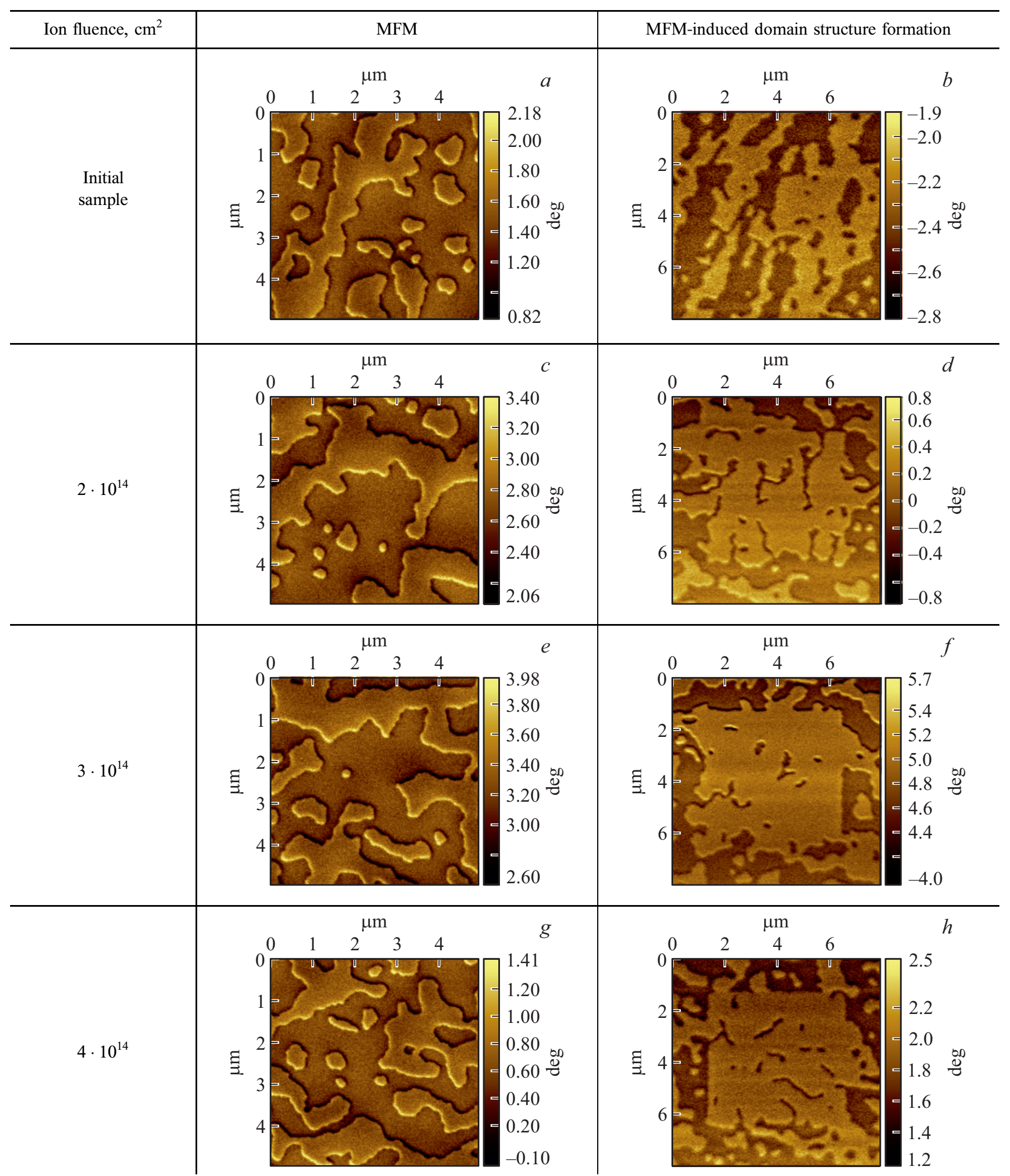

Рис. 4. МСМ-изображения исходного и облученного ионами $\mathrm{He}^{+}(20 \mathrm{keV})$ с различными флюенсами образцов пленок СоРt $(2 / 5)$, полученные двумя способами сканирования (зондом с покрытием CoPt - (MCM) и зондом Nanosensor (MCM-создание доменной структуры)) 
щий притяжению зонда, внутри которого наблюдались скирмионы - мелкие круглые изолированные домены с „обратной“ намагниченностью (темные объекты).

После ионного облучения пленок $\operatorname{CoPt}(3 / 5)$ при флюенсе $2 \cdot 10^{14} \mathrm{~cm}^{-2}$ количество образовавшихся скирмионов увеличивается (рис. $3, f$ ). При повышении флюенса до $3 \cdot 10^{14} \mathrm{~cm}^{-2}$ образуется наибольшее число изолированных доменов (рис. 3,g). При флюенсе $4 \cdot 10^{14} \mathrm{~cm}^{-2}$ наблюдается „вытягивание“ доменов и начало „возвращения“ к лабиринтной доменной структуре (рис. $3, h$ ). Дальнейшее увеличение флюенса $\left(\geq 5 \cdot 10^{14} \mathrm{~cm}^{-2}\right)$ приводит к уменьшению коэрцитивного поля пленки и исчезновению скирмионов. Зонд локально воздействует на доменную структуру, но она практически сразу возвращается в размагниченное состояние [23].

MCМ-измерения исходной пленки $\operatorname{CoPt}(2 / 5)$ магнитным зондом с высоким значением магнитного момента не выявили образования скирмионов. Однако, уже при наименьшем флюенсе $2 \cdot 10^{14} \mathrm{~cm}^{-2}$ картина изменяется: пленка $\operatorname{CoPt}(2 / 5)$ начинает перемагничиваться под действием магнитного поля зонда Nanosensor. При этом образуются темные достаточно локальные области, но более широкие, чем 360-градусные доменные границы (рис. 4,f). Аналогичная картина сохраняется и при облучении ионами с флюенсом $3 \cdot 10^{14} \mathrm{~cm}^{-2}$ (рис. $4, g$ ). Для пленки $\operatorname{CoPt}(2 / 5)$, облученной $\mathrm{He}^{+}$с флюенсом $4 \cdot 10^{14} \mathrm{~cm}^{-2}$, на МСМ-изображении помимо небольшого числа изолированных круглых доменов (скирмионов) наблюдаются узкие полоски с „обратной“ намагниченностью (шириной $\sim 100 \mathrm{~nm}$ ), которые интерпретируются как 360-градусные доменные стенки или 1D-скирмионы (рис. $4, h$ ).

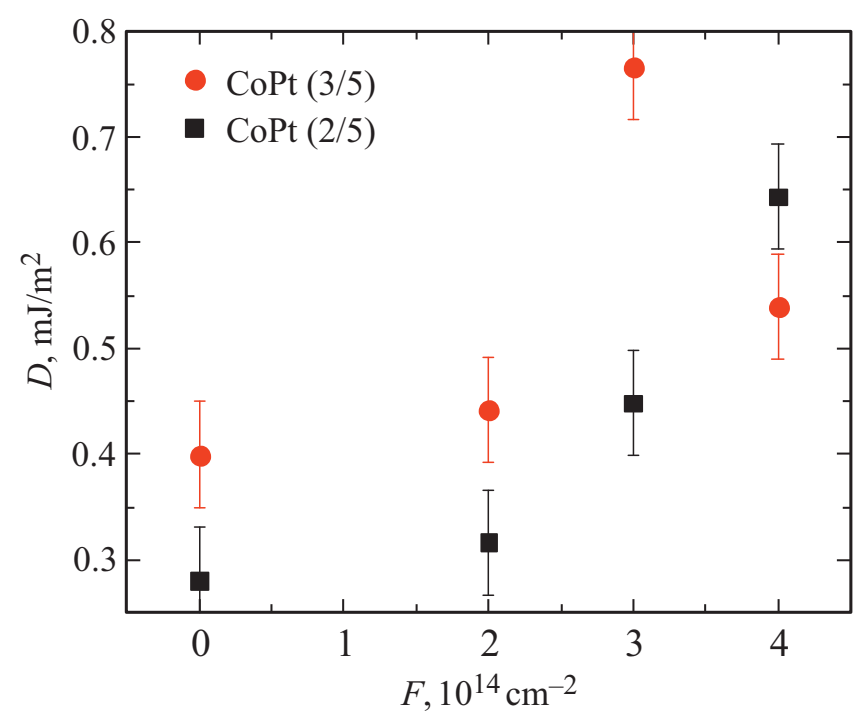

Рис. 5. Зависимости постоянной взаимодействия Дзялошинского-Мория, рассчитанной по результатам исследований исходных и облученных пленок методом мандельштамбриллюэновской спектроскопии, от флюенса ионов для пленок $\operatorname{CoPt}(3 / 5)$ и $\operatorname{CoPt}(2 / 5)$.
Параметры исходных и облученных дозой $F$ пленок (сдвиг между стоксовой и антистоксовой компонентами спектра, $\Lambda$, и константа ВДМ, $D$ ), полученные методом мандельштамбриллюэновской спектроскопии

\begin{tabular}{l|c|c|c|c|c|c|c|c}
\hline \multicolumn{1}{|c|}{ Параметр } & \multicolumn{4}{|c|}{$\operatorname{CoPt}(2 / 5)$} & \multicolumn{4}{c}{$\operatorname{CoPt}(3 / 5)$} \\
\hline$F, 10^{14} \mathrm{~cm}^{-2}$ & 0 & 2 & 3 & $\mathbf{4}$ & 0 & 2 & $\mathbf{3}$ & 4 \\
\hline$\Delta, \mathrm{MHz}$ & 216 & 244 & 345 & $\mathbf{4 9 6}$ & 308 & 340 & $\mathbf{5 9 0}$ & 415 \\
\hline$D, \mathrm{~mJ} / \mathrm{m}^{2}$ & 0.281 & 0.316 & 0.448 & $\mathbf{0 . 6 4 4}$ & 0.400 & 0.442 & $\mathbf{0 . 7 6 6}$ & 0.539
\end{tabular}

Предполагается, что механизм формирования мелких круглых изолированных доменов (скирмионов в слое $\operatorname{CoPt}(3 / 5))$ и таких $1 \mathrm{D}$-скирмионов может быть связан с взаимодействием доменной стенки, передвигаемой зондом, с исходной доменной структурой пленок $\mathrm{CoPt}$ [16].

Исследования исходных и облученных образцов пленок CoPt методом мандельштам-бриллюэновской спектроскопии показали наличие сдвига между стоксовой и антистоксовой компонентами спектра $(\Delta)$ в исходных и облученных образцах $\operatorname{CoPt}(3 / 5)$ и $\operatorname{CoPt}(2 / 5)$ (таблица). Следует отметить, что величина сдвига по абсолютному значению не варьировалась при изменении полярности магнитного поля. Полученные данные позволяют оценить константы взаимодействия ДзялошинскогоМория $(D)$ в пленках $\operatorname{CoPt}(3 / 5)$ и $\operatorname{CoPt}(2 / 5)$ (таблица) и проанализировать влияние ионного облучения на их величину (рис. 5).

Наличие в пленках $\operatorname{CoPt}(3 / 5)$ взаимодействия Дзялошинского-Мория со сравнительно высокими константами свидетельствует в пользу того, что сформированные магнитные круглые домены представляют собой скирмионы. При этом наибольшие значения сдвига стоксовой и антистоксовой компонент спектра $(\Delta=590 \mathrm{MHz})$ и константы ВДМ $\left(D=0.766 \mathrm{~mJ} / \mathrm{m}^{2}\right)$ фиксируются для пленки $\operatorname{CoPt}(3 / 5)$, облученной ионами $\mathrm{He}^{+}$с флюенсом $3 \cdot 10^{14} \mathrm{~cm}^{-2}$. Для образца, облученного с флюенсом ионов $4 \cdot 10^{14} \mathrm{~cm}^{-2}$, константа ВДМ уменьшается до $0.539 \mathrm{~mJ} / \mathrm{m}^{2}$.

Величина константы взаимодействия ДзялошинскогоМория исходной пленки $\operatorname{CoPt}(2 / 5)$ составляет $0.281 \mathrm{~mJ} / \mathrm{m}^{2}$, что почти в 1.5 раза меньше величины $D=0.4 \mathrm{~mJ} / \mathrm{m}^{2}$ для исходной структуры $\operatorname{CoPt}(3 / 5)$. Облученные слои $\operatorname{CoPt}(2 / 5)$ демонстрируют монотонное увеличение сдвига стоксовой и антистоксовой компонент спектра и константы взаимодействия ДзялошинскогоМория для диапазона изменения флюенса $\mathrm{He}^{+}$от $2 \cdot 10^{14}$ до $4 \cdot 10^{14} \mathrm{~cm}^{-2}$. Величина постоянной ВДМ при флюенсе $4 \cdot 10^{14} \mathrm{~cm}^{2}$ превышает $D$ для структуры $\operatorname{CoPt}(3 / 5)$ и достигает $0.644 \mathrm{~mJ} / \mathrm{m}^{2}$.

\section{4. Обсуждение результатов}

Как отмечалось выше, согласно проведенным ранее исследованиям просвечивающей электронной микроско- 
пии, структура исследуемых пленок $\operatorname{CoPt}(3 / 5)$ не показывает „слоистости“, которая характерна для изготовленных методом магнетронного распыления многослойных структур Co/Pt (например, [24]). Под слоистостью понимается четкое разрешение слоев Со и $\mathrm{Pt}$, продемонстрированное на изображении ПЭМ [24]. Этот факт обусловлен, по-видимому, малой толщиной (сопоставимой с монослоем) чередующихся атомных слоев кобальта и платины, достаточно высокой температурой $\left(200^{\circ} \mathrm{C}\right)$ изготовления структур CoPt при электроннолучевом испарении и длительным временем формирования слоя (более $1 \mathrm{~h}$ ). По-видимому, при таких условиях происходит перемешивание атомов Со и $\mathrm{Pt}$, причем можно полагать, что для структур с меньшей толщиной слоя Со $(0.2 \mathrm{~nm})$ полное перемешивание также будет происходить.

Выбранные нами условия облучения ионами $\mathrm{He}^{+}$ не вносят значительных изменений в кристаллическую структуру CoPt. Согласно работам [25-29], для ионов $\mathrm{He}^{+}$в диапазоне энергий от 5 до $150 \mathrm{keV}$ протяженные каскады столкновений отсутствуют, а структурные изменения ограничиваются областью вблизи траектории иона. Ионы останавливаются достаточно глубоко в подложке (средний проецированный пробег составляет $128 \mathrm{~nm}$ ), а процесс облучения включает в себя отдачу, ограниченную одним (или редко двумя) атомными расстояниями, что приводит к замещению атомов: $\mathrm{Co} \rightarrow \mathrm{Co}$, $\mathrm{Pt} \rightarrow \mathrm{Pt}, \mathrm{Co} \rightarrow \mathrm{Pt}$ или $\mathrm{Pt} \rightarrow \mathrm{Co}$. В результате такого „мягког" процесса облучения сохраняются исходная кристаллографическая структура и микроструктура (размер зерна). Шероховатость поверхности в результате облучения не увеличивается [29].

Вместе с тем в облученных структурах CoPt образуются дефекты (преимущественно точечные). Согласно сделанным нами расчетам с использованием программы SRIM, концентрация таких дефектов при энергии ионов $\mathrm{He}^{+} 20 \mathrm{keV}$ с флюенсом $3 \cdot 10^{14} \mathrm{~cm}^{-2}$ составляет $\sim(1-7) \cdot 10^{20} \mathrm{~cm}^{-3}$ (менее или порядка $1 \%$ от количества атомов в одном кубическом сантиметре).

Авторы [29] отмечают, что в процессе облучения $\mathrm{He}^{+}$ многослойных структур $\mathrm{Pt} / \mathrm{Co} / \mathrm{Pt}$ возникает анизотропия в распределении атомов Со и Pt. Атомы Со более активно диффундируют в слой платины, чем атомы платины в слой кобальта. Атомы кобальта, которые попадают в результате ионной имплантации $\mathrm{He}^{+}$в нижний слой $\mathrm{Pt}$, могут проникать на несколько межатомных расстояний. При этом атомы Со, попавшие в результате ионного облучения в верхний слой Pt (атомы отдачи) могут преодолеть не более одного межатомного расстояния. Соответственно, в [29] заключают, что верхняя граница слоя кобальта со слоем платины становится „шероховатой“ (неровной), а в области нижней границы $\mathrm{Co} / \mathrm{Pt}$ образуется сплав CoPt. Другими словами, наблюдается ассимметрия в перемешивании атомов на границах слоев кобальта и платины. Этот эффект может быть наиболее вероятной причиной появления и/или усиления взаимодействия Дзялошинского-Мория и возникновения скирмионов.

В случае исследуемых нами структур $\operatorname{CoPt}(3 / 5)$ и $\operatorname{CoPt}(2 / 5)$, как показывают расчеты методом SRIM, ионное облучение при выбранных условиях (тип иона, энергия и флюенс) приводит к ассиметричному изменению концентрации атомов Со и $\mathrm{Pt}$ (см. рис. 1). Это может вызывать снижение перпендикулярной анизотропии и активацию образования скирмионных состояний вследствие усиления ВДМ. Формирование скирмионов зависит от энергии доменной стенки, которая, в свою очередь, зависит от постоянной взаимодействия Дзялошинского-Мория [30]. С увеличением постоянной ВДМ энергия доменной стенки понижается, и возникают оптимальные условия для образования доменных структур типа скирмионов под воздействием локального поля магнитного зонда.

\section{5. Заключение}

В работе продемонстрировано использование управляемого радиационного воздействия (имплантации ионов $\mathrm{He}^{+}$с энергией $20 \mathrm{keV}$ ) как способа модифицирования магнитных свойств и доменной структуры пленок CoPt различного состава, сформированных методом электронно-лучевого испарения в высоком вакууме.

Обнаружено, что при сканировании облученных пленок магнитным зондом атомно-силового микроскопа происходит перестройка их доменной структуры: для сплава $\mathrm{Co}_{0.45} \mathrm{Pt}_{0.55}$ с увеличением флюенса ионов до $3 \cdot 10^{14} \mathrm{~cm}^{-2}$ образуется наибольшее число круглых изолированных доменов (скирмионов), а для облученных пленок $\mathrm{Co}_{0.35} \mathrm{Pt}_{0.65}$ при флюенсе $\mathrm{He}^{+} 4 \cdot 10^{14} \mathrm{~cm}^{2}$, помимо изолированных круглых доменов, наблюдаются 360-градусные доменные стенки (1D-скирмионы). При этом исследования исходных и облученных образцов пленок $\mathrm{CoPt}$ методом мандельштам-бриллюэновской спектроскопии выявили наличие сдвига между стоксовой и антистоксовой компонентами спектра в исходных и облученных образцах. Анализ полученных данных показал, что наибольшее значение константы взаимодействия Дзялошинского-Мория - $0.766 \mathrm{~mJ} / \mathrm{m}^{2}$ для пленки $\mathrm{Co}_{0.45} \mathrm{Pt}_{0.55}$ наблюдается при облучении ионами $\mathrm{He}^{+} \mathrm{c}$ флюенсом $3 \cdot 10^{14} \mathrm{~cm}^{-2}$. В свою очередь, облученные слои $\mathrm{Co}_{0.35} \mathrm{Pt}_{0.65}$ демонстрируют монотонное увеличение константы взаимодействия Дзялошинского-Мория (достигает $0.644 \mathrm{~mJ} / \mathrm{m}^{2}$ ) с увеличением флюенса ионов $\mathrm{He}^{+}$ от $2 \cdot 10^{14}$ до $4 \cdot 10^{14} \mathrm{~cm}^{-2}$.

C использованием расчетов методом SRIM продемонстрировано, что ионное облучение при выбранных условиях (тип иона, энергия и флюенс) приводит к ассиметричному изменению концентрации атомов Со и Pt в пленках CoPt. Такое ассимметричное перемешивание атомов Со и $\mathrm{Pt}$ способствует понижению перпендикулярной магнитной анизотропии и усилению взаимодействия Дзялошинского-Мория. В свою очередь 
повышение константы взаимодействия ДзялошинскогоМория понижает энергию доменной стенки, и тем самым облегчается формирование скирмионо-подобных доменных структур локальным полем магнитного зонда.

\section{Финансирование работы}

Работа выполнена при поддержке грантов президента РФ (МК-445.2020.2, МД-1708.2019.2), госзадания Министерства науки и высшего образования Российской Федерации (проект № 075-03-2020-191/5) и гранта РФФИ (№ 18-29-19137_мк). МСМ исследования выполнены в рамках госзадания (проект № 0030-2019-0001) при частичной поддержке РФФИ (грант № 19-29-03049-мк). Исследование невзаимного распространения дипольно-связанных спиновых волн методом мадельштам-бриллюэновской спектроскопии выполнено при поддержке гранта РФФИ № 18-2927026 и грантов Президента РФ (МК-1870.2020.9, СП-2819.2018.5).

\section{Конфликт интересов}

Авторы заявляют, что у них нет конфликта интересов.

\section{Список литературы}

[1] H. Yang, A. Thiaville, S. Rohart, A. Fert, M. Chshiev. Phys. Rev. Lett. 115, 267210 (2015).

[2] K. Zeissler, M. Mruczkiewicz, S. Finizio, J. Raabe, P.M. Shepley, A.V. Sadovnikov, S.A. Nikitov, K. Fallon, S. McFadzean, S. McVitie, T.A. Moore, G. Burnell, C.H. Marrows. Sci. Rep. 7, 15125 (2017).

[3] Г.С. Кандаурова. Сорос.образоват. журн. 3, 1, 100 (1997).

[4] V.M. Uzdin, M.N. Potkina, I.S. Lobanov, P.F. Bessarab, H. Jónsson. Physica B 549, 6 (2018).

[5] L. Desplat, D. Suess, J.-V. Kim, R.L. Stamps. Phys. Rev. B 98, 134407 (2018).

[6] K. Fallon, S. Hughes, K. Zeissler, W. Legrand, F. Ajejas, D. Maccariello, S. McFadzean, W. Smith, D. McGrouther, S. Collin, N. Reyren, V. Cros, C.H. Marrows, S. McVitie. Small 16, 13, 1907450 (2020).

[7] S. Zhang, A.K. Petford-Long, C. Phatak. Sci. Rep. 6, 31248 (2016).

[8] В.Л. Миронов, Р.В. Горев, О.Л. Ермолаева, Н.С. Гусев, Ю.В. Петров. ФТТ 61, 9, 1644 (2019).

[9] И.Л. Калентьева, О.В. Вихрова, Ю.А. Данилов, М.В. Дорохин, Ю.А. Дудин, А.В. Здоровейщев, А.В. Кудрин, М.П. Темирязева, А.Г. Темирязев, С.А. Никитов, А.В. Садовников. ФTT 61, 9, 1694 (2019).

[10] А.И. Бобров, Ю.А. Данилов, М.В. Дорохин, А.В. Здоровейщев, Н.В. Малехонова, Е.И. Малышева, Д.А. Павлов, С. Сайед. Поверхность. Рентгеновские, синхротронные и нейтронные исследования 7, 57 (2015).

[11] А.В. Здоровейщев, М.В. Дорохин, П.Б. Демина, А.В. Кудрин, О.В. Вихрова, М.В. Ведь, Ю.А. Данилов, И.В. Ерофеева, Р.Н. Крюков, Д.Е. Николичев. ФТП 49, 12, 1649 (2015).
[12] А.В. Здоровейщев. Труды IX Всероссийской школысеминара студентов, аспирантов и молодых ученых по направлению „Диагностика наноматериалов и наноструктур“ (18-22 сентября 2017 г. РГРТУ, Рязань). Т. 1, 72 (2017).

[13] А.В. Здоровейщев, О.В. Вихрова, П.Б. Демина, М.В. Дорохин, А.В. Кудрин, А.Г. Темирязев, М.П. Темирязева. ФТТ 61, 9, 1628 (2019).

[14] А.В. Здоровейщев, М.В. Дорохин, О.В. Вихрова, П.Б. Демина, А.В. Кудрин, А.Г. Темирязев, М.П. Темирязева. ФТТ 58, 11, 2186 (2016).

[15] А.В. Кудрин, М.В. Дорохин, А.В. Здоровейщев, П.Б. Демина, О.В. Вихрова, И.Л. Калентьева, М.В. Ведь. ФТТ 59, 11, 2203 (2017).

[16] М.П. Темирязева, А.В. Здоровейщев, О.В. Вихрова, А.В. Кудрин, А.В. Садовников, С.А. Никитов, А.Г. Темирязев. Материалы XXIV Междунар. симпозиума „Нанофизика и Наноэлектроника“ ( 10-13 марта, 2020 г. Нижний Новгород). Т. 1, 273 (2020).

[17] А.Г. Темирязев, М.П. Темирязева, А.В. Здоровейщев, О.В. Вихрова, М.В. Дорохин, П.Б. Демина, А.В. Кудрин. ФTT 60, 11, 2158 (2018).

[18] http://www.SRIM.org

[19] http://www.asu.edu/clas/csss/NUE/FIBSputterCalcYamamura.html

[20] A.V. Zdoroveyshchev, O.V. Vikhrova, P.B. Demina, M.V. Dorokhin, A.V. Kudrin, A.G. Temiryazev, M.P. Temiryazeva. Int. J. Nanosci. 18, 3-4, 1940019 (2019).

[21] A.V. Sadovnikov, E.N. Beginin, K.V. Bublikov, S.V. Grishin, S.E. Sheshukova, Yu.P. Sharaevskii, S.A. Nikitov. J. Appl. Phys. 118, 203906 (2015).

[22] K. Everschor-Sitte, J. Masell, R.M. Reeve, M. Kläui. J. Appl. Phys. 124, 240901 (2018).

[23] И.Л. Калентьева, О.Л. Вихрова, Ю.А. Данилов, Ю.А. Дудин, А.В. Здоровейщев, А.В. Кудрин, Ю.М. Кузнецов, М.П. Темирязева, А.Г. Темирязев. Материалы XXIV Междунар. симпозиума „Нанофизика и Наноэлектроника“ (10-13 марта 2020 г. Нижний Новгород). Т. 1, 207 (2020).

[24] J. Zarpellon, H. Jaffres, J. Frougier, C. Deranlot, J.M. George, D.H. Mosca, A. Lemaitre, F. Freimuth, Q.H. Duong, P. Renucci, X. Marie. Phys. Rev. B 86, 205314 (2012).

[25] C. Chappert, H. Bernas, J. Ferré, V. Kottler, J.-P. Jamet, Y. Chen, E. Cambril, T. Devolder, F. Rousseaux, V. Mathet, H. Launois. Science 280, 5371, 1919 (1998).

[26] J. Ferré, T. Devolder, H. Bernas, J.P. Jamet, V. Repain, M. Bauer, N. Vernier, C. Chappert. J. Phys. D 36, 24, 3103 (2003).

[27] T. Devolder, C. Chappert, V. Mathet, H. Bernas, Y. Chen, J.P. Jamet, J. Ferré. J. Appl. Phys. 87, 12, 8671 (2000).

[28] T. Devolder, S. Pizzini, J. Vogel, H. Bernas, C. Chappert, V. Mathet, M. Borowski. Eur. Phys. J. B 22, 2, 193 (2001).

[29] J. Fassbender, D. Ravelosona, Y. Samson. J. Phys. D 37, 16, R179 (2004).

[30] T. Nozaki, M. Konoto, T. Nozaki, H. Kubota, A. Fukushima, S. Yuasa. AIP Advances 10, 035130 (2020).

Редактор Т.Н. Василевская 